\title{
Metallic porous electrodes enable efficient bicarbonate electrolysis
}

Zishuai Zhang, ${ }^{1}$ Faezeh Habibzadeh, ${ }^{1}$ Danielle A. Salvatore, ${ }^{2}$ Shaoxuan Ren, ${ }^{1}$ Eric W. Lees, ${ }^{2}$ and Curtis P. Berlinguette*1,2,3,4

${ }^{1}$ Department of Chemistry, The University of British Columbia, 2036 Main Mall, Vancouver, British Columbia, V6T 1Z1, Canada.

${ }^{2}$ Department of Chemical and Biological Engineering, The University of British Columbia, 2360 East Mall, Vancouver, British Columbia, V6T 1Z3, Canada.

${ }^{3}$ Stewart Blusson Quantum Matter Institute, The University of British Columbia, 2355 East Mall, Vancouver, British Columbia, V6T 1Z4, Canada.

${ }^{4}$ Canadian Institute for Advanced Research (CIFAR), 661 University Avenue, Toronto, M5G 1M1, Ontario, Canada.

*Corresponding author: Curtis P. Berlinguette (berling@chem.ubc.ca) 


\section{Highlights:}

- The electrolysis of bicarbonate solutions presents the opportunity to utilize liquid feedstocks that are easier to engineer than systems that require gaseous $\mathrm{CO}_{2}$

- Porous silver foam electrodes enables the electrolysis of bicarbonate solutions at rates commensurate with gaseous $\mathrm{CO}_{2}$ feedstocks

- The efficient electrolysis of bicarbonate provides a viable path for converting air capture solutions into useful products without the need for costly separations and pressurization steps

\section{Context \& Scale}

Developing technologies to store intermittent wind and solar energy is a key step towards decarbonizing the global economy. The $\mathrm{CO}_{2}$ reduction reaction $\left(\mathrm{CO}_{2} \mathrm{RR}\right)$ is a promising strategy that enables renewable energy to be stored in chemicals and fuels using atmospheric or emitted $\mathrm{CO}_{2}$. Pilot-scale electrolyzers that use a gaseous $\mathrm{CO}_{2}$ feedstock (instead of $\mathrm{CO}_{2}$ dissolved in water) can mediate high rates of $\mathrm{CO}_{2} \mathrm{RR}$, but this approach is challenged by the energy-intensive processes required to produce purified, high pressure $\mathrm{CO}_{2}$ from carbon capture.

We show in this work the electrochemical conversion of carbon capture solutions (i.e., bicarbonate) directly into chemical building blocks (i.e., $\mathrm{CO}+\mathrm{H}_{2}$ ) using highly-active and robust metallic electrodes. This study demonstrates bicarbonate electrolysis as a practical strategy for storing renewable energy in carbon chemicals while bypassing $\mathrm{CO}_{2}$ separation and pressurization processes in upstream $\mathrm{CO}_{2}$ capture. capture. 


\section{Summary}

We demonstrate here that a porous free-standing silver foam cathode in an electrolytic flow cell mediates efficient electrolysis of $3.0 \mathrm{M}$ bicarbonate solutions into $\mathrm{CO}$. These results have direct implications for carbon capture schemes where $\mathrm{OH}^{-}$solutions react with $\mathrm{CO}_{2}$ to form bicarbonate-rich solutions that need to be treated to recycle the sorbent and recover the $\mathrm{CO}_{2}$. Our study shows a viable path for replacing the high-temperature thermal process currently used to recover $\mathrm{CO}_{2}$ from these carbon capture solutions by using electricity to drive the conversion of bicarbonate into $\mathrm{CO}_{2}$ and subsequently into $\mathrm{CO}$. The use of free-standing porous silver electrodes was found to yield electrolysis performance parameters (e.g., a Faradaic efficiency for $\mathrm{CO}$ production, $\mathrm{FE}_{\mathrm{CO}}$, of $78 \%$ at $100 \mathrm{~mA} \mathrm{~cm}^{2} ;<3 \%$ performance loss after $80 \mathrm{~h}$ operation) that are superior to results obtained in bicarbonate electrolyzers that utilize conventional carbon-based gas diffusion electrodes (GDEs) designed for gaseous $\mathrm{CO}_{2}$ fed electrolyzers. These performance metrics are comparable to any electrolytic flow cell fed directly with a $\mathrm{CO}_{2}$ feedstock, with the added benefit of not requiring an energy-intensive pressurization step that would be necessary for the electrolysis of gaseous $\mathrm{CO}_{2}$. These findings represent a potentially important step in closing the carbon cycle.

\section{Keywords}

Bicarbonate electrolysis; $\mathrm{CO}_{2}$ reduction reaction; flow cell; silver foam; gas diffusion electrode. 
Table of contents graphic

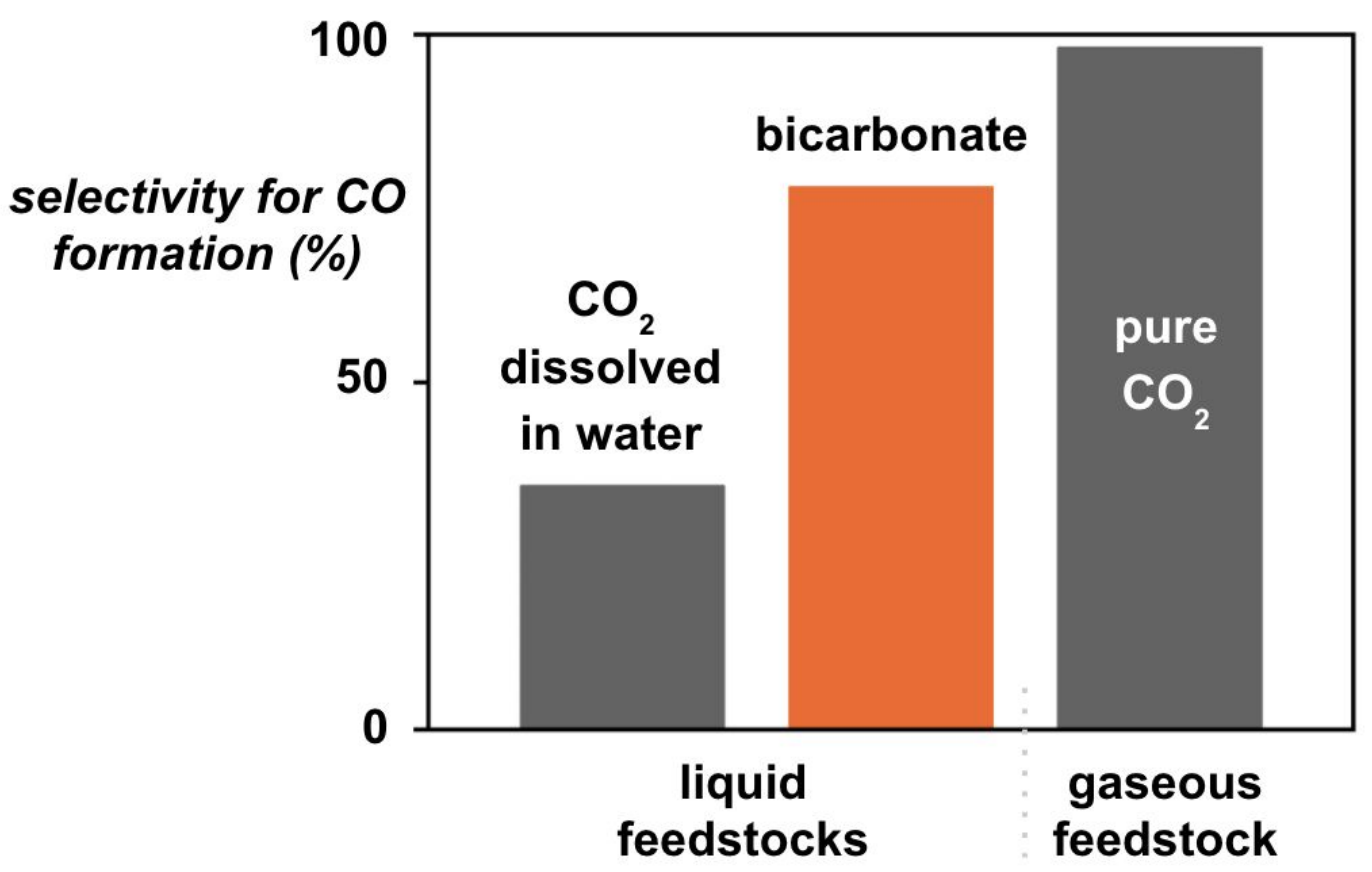




\section{Introduction}

In order to utilize $\mathrm{CO}_{2}$ captured from the atmosphere or a point source, the captured $\mathrm{CO}_{2}$ needs to be extracted from the sorbent in such a way that the sorbent can be recycled to capture additional $\mathrm{CO}_{2}$. Schemes that rely on basic solutions such as $\mathrm{KOH}$ to capture $\mathrm{CO}_{2}$ by forming carbonate (Eqs. 1 and 2) use a high temperature calcination step $\left(>900{ }^{\circ} \mathrm{C}\right.$ ) to subsequently liberate $\mathrm{CO}_{2}$ (which can then be stored or utilized) from the carbonate salt with the concomitant recovery of the $\mathrm{OH}^{-}$sorbent (Eqs. 3 and 4, Figure 1). ${ }^{1}$ This recovery process involving the thermal decomposition of $\mathrm{CaCO}_{3}$ at $900{ }^{\circ} \mathrm{C}$ is expensive because it uses two preheat cyclones along with a calciner in succession that are both energy and capital intensive. ${ }^{1}$ One promising option for using this $\mathrm{CO}_{2}$ is to electrolytically convert it into chemicals or fuels of economic value (e.g., CO) using renewable electricity (Eq. 5, Figure 1)., ${ }^{2,3}$ While there have been many recent advances in electrolytic $\mathrm{CO}_{2}$ reduction, ${ }^{2,4-7}$ the electrolysis of $\mathrm{CO}_{2}$ will likely require an energy-intensive $\mathrm{CO}_{2}$ pressurization step prior to electrolysis in order to achieve meaningful reaction rates (Figure 1$).^{8}$

$$
\begin{array}{cll}
\text { CO } \text { capture: } & \mathrm{CO}_{2(\mathrm{~g})}+2 \mathrm{KOH}_{(\mathrm{aq})} \rightleftharpoons \mathrm{K}_{2} \mathrm{CO}_{3(\mathrm{aq})}+\mathrm{H}_{2} \mathrm{O}_{(\mathrm{l})},\left(\mathrm{pK}_{\mathrm{b}} 3.7\right) & \text { Eq.1 } \\
\text { KOH regeneration: } & \mathrm{K}_{2} \mathrm{CO}_{3(\mathrm{aq})}+\mathrm{Ca}(\mathrm{OH})_{2(\mathrm{~s})} \rightleftharpoons \mathrm{CaCO}_{3(\mathrm{~s})}+2 \mathrm{KOH}_{(\mathrm{aq})} & \text { Eq.2 } \\
\mathrm{CO} \text { recovery: } & \mathrm{CaCO}_{3(\mathrm{~s})} \rightleftharpoons \mathrm{CO}_{2(\mathrm{~g})}+\mathrm{CaO}(\mathrm{s}) & \text { Eq.3 } \\
\text { Sorbent regeneration: } & \mathrm{CaO}_{(\mathrm{s})}+\mathrm{H}_{2} \mathrm{O}_{(\mathrm{l})} \rightleftharpoons \mathrm{Ca}(\mathrm{OH})_{2(\mathrm{~s})} & \text { Eq.4 } \\
\mathrm{CO}_{2} \text { reduction reaction }\left(\mathrm{CO}_{2}\right. \text { RR): } & \mathrm{CO}_{2(\mathrm{~g})}+\mathrm{H}_{2} \mathrm{O}_{(\mathrm{l})}+2 \mathrm{e}^{-} \rightleftharpoons \mathrm{CO}_{(\mathrm{g})}+2 \mathrm{OH}_{(\mathrm{aq})}^{-} & \text {Eq.5 }
\end{array}
$$




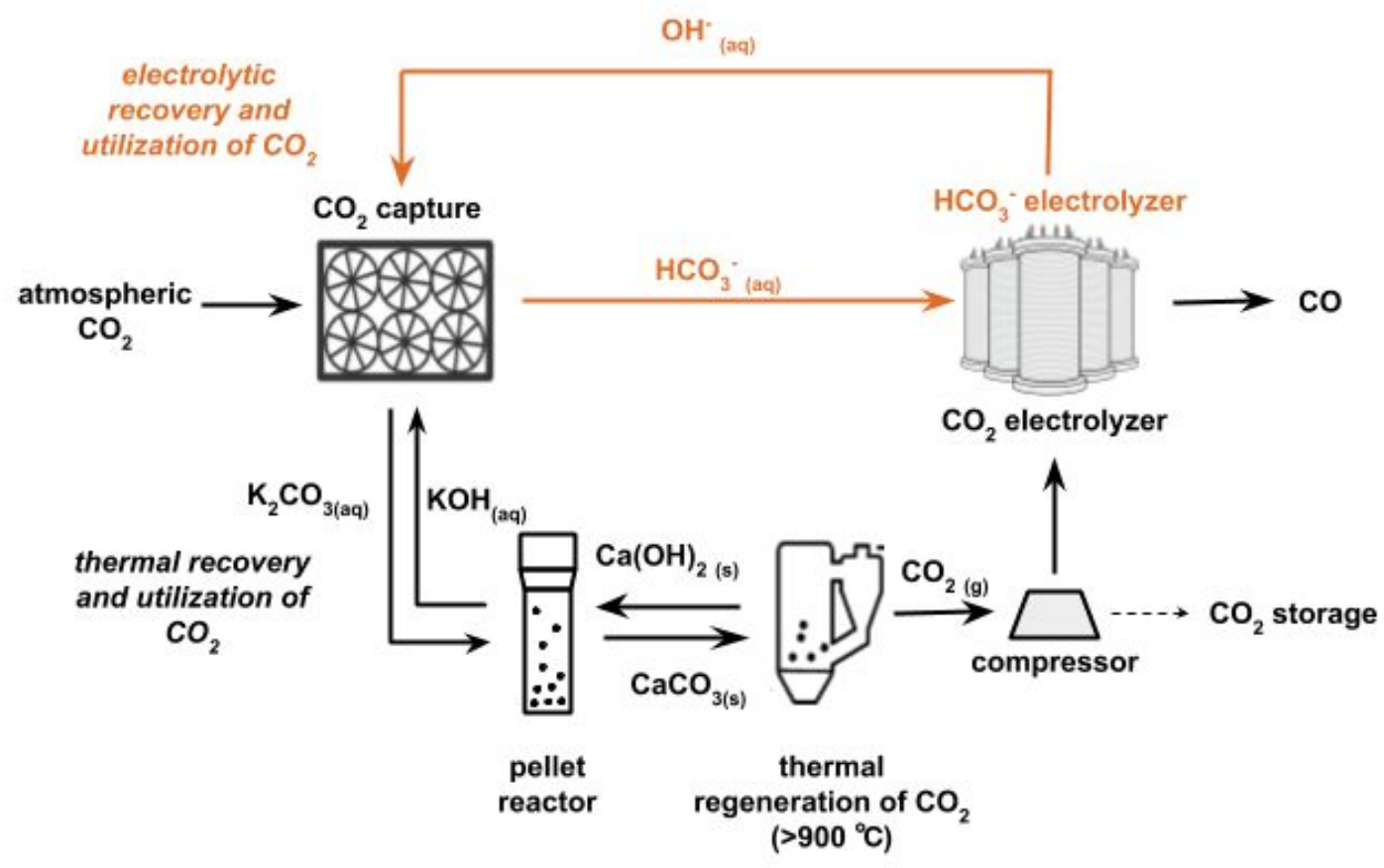

Figure 1. Thermal $\mathrm{CO}_{2}$ and sorbent recovery (black) and electrolytic recovery of $\mathrm{CO}_{2}$ (orange) processes to convert captured atmospheric $\mathrm{CO}_{2}$ to $\mathrm{CO}$. For the direct air capture process, atmospheric $\mathrm{CO}_{2(\mathrm{~g})}$ is captured by hydroxide solutions and then regenerated from $\mathrm{CaCO}_{3(\mathrm{~s})}$ in a high temperature calcination step $\left(>900^{\circ} \mathrm{C}\right)$. The recovered $\mathrm{CO}_{2}$ typically needs to be pressurized prior to electrolysis or storage (black). For the bicarbonate electrolysis process, carbon capture solution $\left(\mathrm{HCO}_{3}^{-}\right)$is electrochemically converted to $\mathrm{CO}$ without the need for energy intensive calcination and pressurization steps (orange). The hydroxide byproduct can be recycled for use as a carbon capture solution in the bicarbonate electrolysis pathway.

Our program is therefore seeking methods that avoid the calcination and pressurizations steps by developing reactor architectures that utilize bicarbonate solutions obtained during the $\mathrm{CO}_{2}$ capture process as the cathodic feedstock while regenerating the $\mathrm{OH}^{-}$sorbent for subsequent carbon capture (Figure 1, orange loop). ${ }^{1,9-12}$ This proposed carbon capture and utilization scheme links $\mathrm{CO}_{2}$ electrochemistry with upstream carbon capture without requiring high temperature or pressurization processes. A major technical challenge associated with this scheme is that bicarbonate cannot be directly electrochemically reduced. Bicarbonate must first react with protons to form $\mathrm{CO}_{2}$, which is the 
electrocatalytically active species that can be reduced to $\mathrm{CO}$ or other carbon-containing products. The management of this acid-base chemistry (Eq. 6) in tandem with electrochemistry (Eq. 5) therefore requires the careful design of an electrolyzer before liquid bicarbonate feedstocks can be deemed suitable for electrolysis. It is for these reasons that we are seeking ways to have protons delivered from a membrane, such as a bipolar membrane (BPM), for reaction with bicarbonate to form electrocatalytically active $\mathrm{CO}_{2}$ at the membrane-catalyst interface. ${ }^{11,13}$

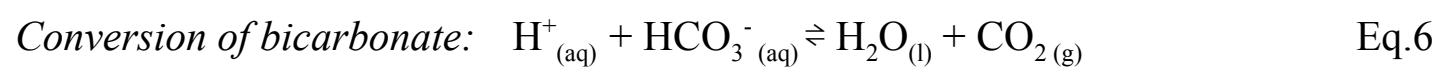

For electrolyzers that use a gaseous $\mathrm{CO}_{2}$ feedstock, gas diffusion electrodes (GDEs) are designed to support an electrocatalyst layer while also managing the water content at the cathodic side of the membrane electrode assembly (MEA). Flooding of the MEA with water needs to be avoided because it decreases the performance of electrolyzers by hindering $\mathrm{CO}_{2}$ access to the catalyst layer. Excess water also promotes the undesirable hydrogen evolution reaction (HER) to occur over the $\mathrm{CO}_{2}$ reduction reaction $\left(\mathrm{CO}_{2} \mathrm{RR}\right) .{ }^{14}$ GDEs used for electrolysis of gaseous $\mathrm{CO}_{2}$ typically consist of a three-layer structure containing: (i) a conductive, porous carbon cloth positioned against the cathodic flow plate; (ii) a conductive and hydrophobic microporous layer (MPL) of carbon black treated with polytetrafluoroethylene (PTFE); and (iii) a catalyst layer between the MPL and the membrane (Figure 2a). The hydrophobicity of the MPL serves to mitigate flooding, and the mitigated flooding helps reduce ohmic losses and increases the accessible active area of the catalyst layer. ${ }^{15}$ 
(a) gas diffusion electrode (GDE)

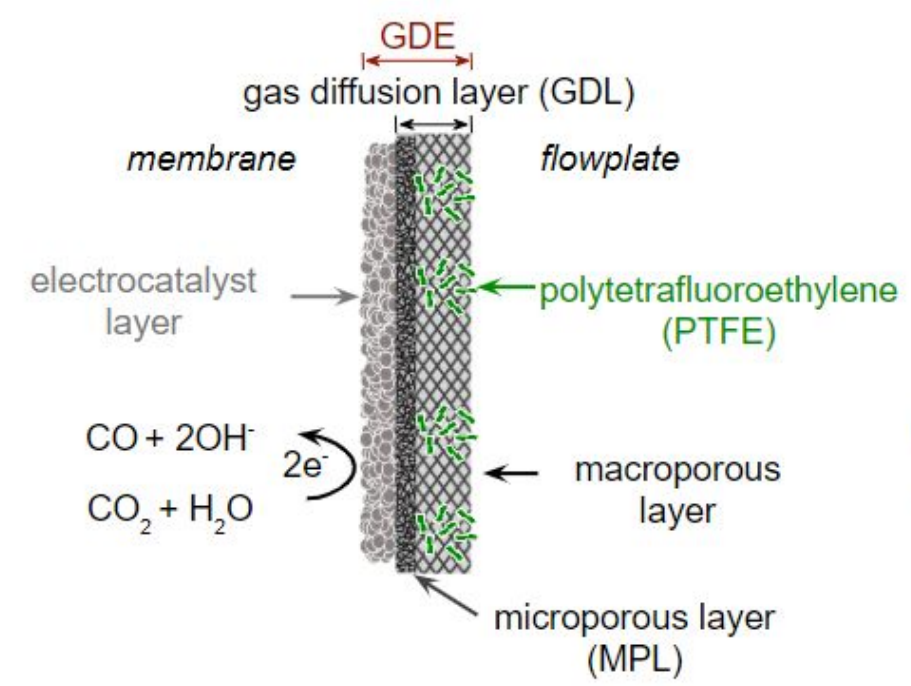

freestanding GDE

(this work)

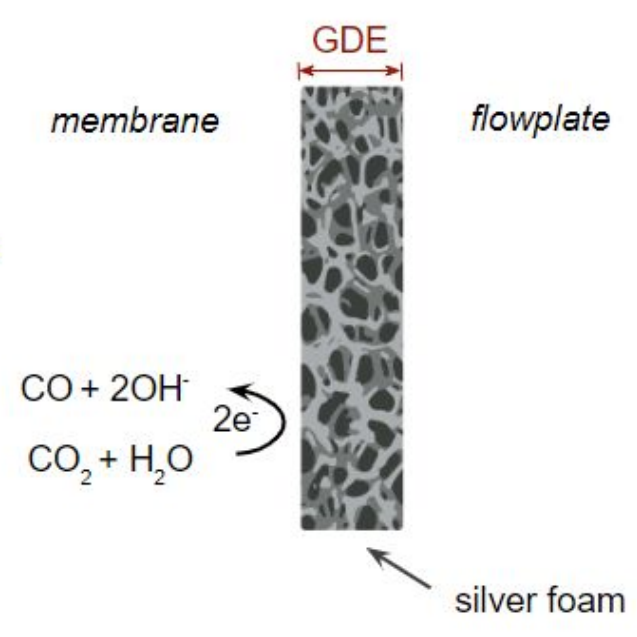

(b) silver foam electrodes under investigation
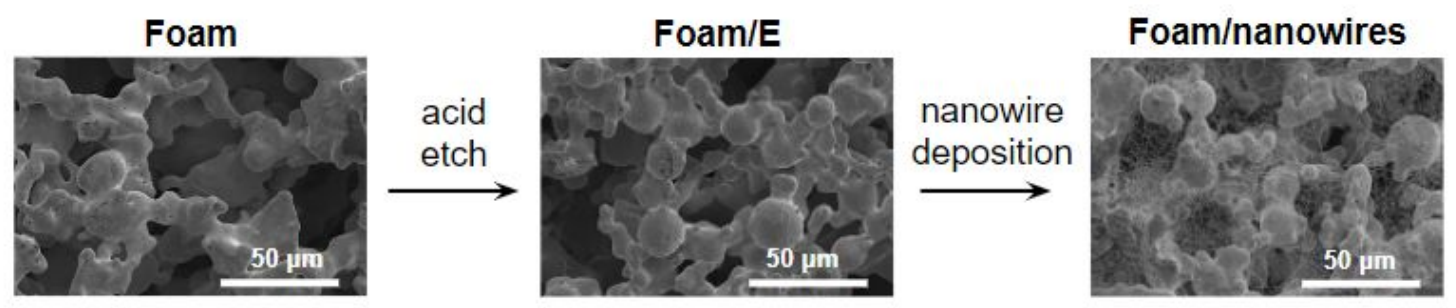

Figure 2. Schematics of a conventional GDE and a free-standing silver foam GDE. (a) Schematic depictions of the conventional GDE cathode with a microporous layer (MPL) and polytetrafluoroethylene (PTFE) treatment, and the free-standing silver foam GDE. Bicarbonate ions are the reactants for in-situ $\mathrm{CO}_{2}$ generation at the membrane-catalyst interface, and the produced $\mathrm{CO}_{2}$ is subsequently reduced to $\mathrm{CO}$ (see Eqs. 5 and 6). (b) SEM images of the Foam, Foam/E and the Foam/nanowires GDEs under investigation.

While these GDE designs are effective for the electrolysis of gaseous $\mathrm{CO}_{2}$, they are not necessarily effective for the electrolysis of liquid feedstocks such as bicarbonate. Consider that commercial liquid-fed electrolyzer systems (e.g., water electrolyzers and chlor-alkali electrolyzers), ${ }^{16,17}$ use free-standing electrodes and not GDEs as described above. Free-standing porous nickel (alloys), or steel electrodes coated with nickel, are capable of operating at lower overpotentials with longer lifetimes relative to GDEs in alkaline water electrolyzers. ${ }^{18,19}$ Commercial chlor-alkali electrolyzers also use 
titanium-based and nickel-based free-standing electrodes. ${ }^{17,20,21}$ Moreover, hydrophobic GDEs inhibit the transport of solvated $\mathrm{HCO}_{3}^{-}$, therefore adversely affecting the in-situ $\mathrm{CO}_{2}$ generation $\left(i-\mathrm{CO}_{2}\right)$ at the membrane-GDE interface. ${ }^{22}$ Replacing hydrophobic GDEs with metallic porous electrodes is anticipated to facilitate the transport of solvated ions and improve the performance of the bicarbonate electrolyzer. ${ }^{23}$

These collective observations inspired us to test porous free-standing silver foam electrodes for liquid bicarbonate fed electrolysis. Not only these free-standing electrodes simplify the assembly of flow cells relative to conventional GDEs (which require a multi-step fabrication process), these metallic electrodes mediate remarkably effective bicarbonate electrolysis (e.g., a faradaic efficiency for CO production $\left(\mathrm{FE}_{\mathrm{CO}}\right)$ of $72 \pm 3 \%$ at $100 \mathrm{~mA} \mathrm{~cm}^{-2}$ at $20^{\circ} \mathrm{C}$ ) and incur a merely $3 \%$ loss in $\mathrm{FE}_{\mathrm{CO}}$ over $80 \mathrm{~h}$ of sustained electrolysis at $65 \mathrm{~mA} \mathrm{~cm}^{-2}$. These results are superior to that of our control experiments with conventional GDEs (i.e., multilayer structure of a catalyst layer adjacent to a hydrophobic GDL as a support) which yielded peak $\mathrm{FE}_{\mathrm{CO}}$ values of $33 \pm 6 \%$ and suffered from $15 \%$ loss in $\mathrm{FE}_{\mathrm{CO}}$ during our 80 h stability test. We achieved these results with the metallic electrodes by acid-etching and coating the surfaces with silver nanowires to generate higher catalytic activity. We also found that increasing the temperature of the bicarbonate feedstock, and the dynamic equilibria of the solution, suppresses HER and leads to higher $\mathrm{FE}_{\mathrm{CO}}$ values. The bicarbonate electrolyzers reported herein demonstrate comparable performance to state-of-the-art gaseous $\mathrm{CO}_{2}$ fed electrolyzers (Figure 3, Table S2), providing an opportunity to close the current upstream carbon capture loop and avoid the costly calcination and pressurization steps. 


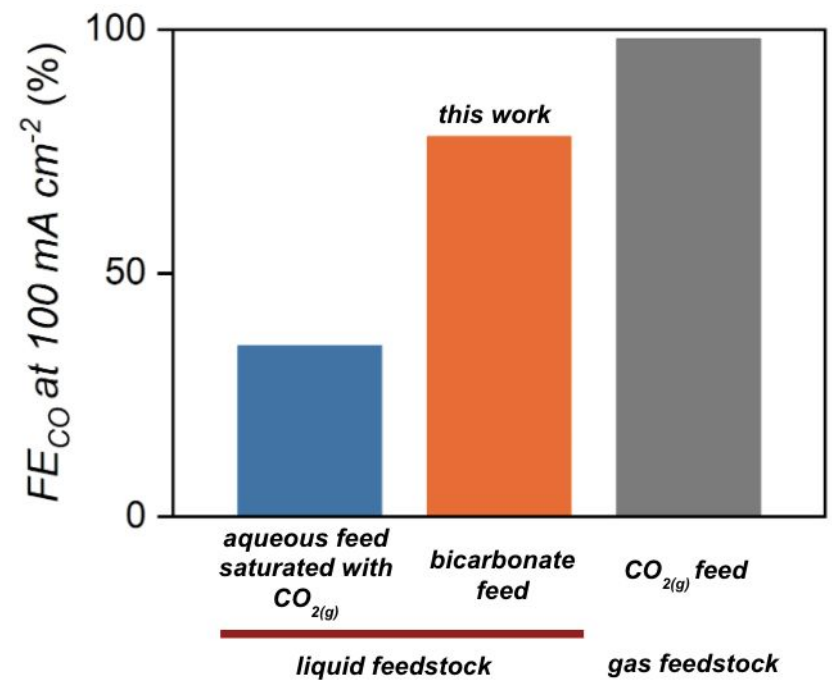

Figure 3. State-of-the-art $\mathrm{FE}_{\mathrm{CO}}$ values for zero-gap electrolyzers designed to reduce $\mathrm{CO}_{2}$ using three different feedstocks: aqueous feedstocks saturated with $\mathrm{CO}_{2}$ (blue), bicarbonate feedstocks (orange), and gaseous $\mathrm{CO}_{2}$ (grey). ${ }^{11,24-30}$ See Table S2 for additional details.

\section{Results and Discussion}

All electrolysis experiments were conducted in a two-electrode MEA flow cell (Figure S1). ${ }^{11,25}$ The MEA consisted of a fully hydrated Fumasep bipolar membrane (BPM) sandwiched between the anode (Ni foam) and the cathode (conventional GDEs or silver foam-based electrodes). The BPM was operated in reverse-bias mode, with the cation exchange layer facing the cathode. ${ }^{13}$ A peristaltic pump delivered 1.0 M KOH to the anode at a constant flow rate of $40 \mathrm{ml} \mathrm{min}^{-1}$. The $3.0 \mathrm{M} \mathrm{KHCO}_{3}$ cathode electrolyte was delivered separately at a constant flow rate of $50 \mathrm{ml} \mathrm{min}^{-1}$. The headspace of the cathode electrolyte reservoir was purged with $\mathrm{N}_{2}$ at $160 \mathrm{sccm}$ over the course of each experiment. Product gases and $\mathrm{N}_{2}$ in the headspace of the cathode electrolyte reservoir were delivered to an in-line gas chromatograph (GC) with data analysis and peak integration completed in PeakSimple software. The temperature of the catholyte reservoir was controlled with a water bath set to $20,40,60$, or $80^{\circ} \mathrm{C}$. The flow cell inlet temperatures were measured using in-line resistance temperature detectors (RTDs). 
The bicarbonate electrolysis experiments were designed to test modifications of the cathodes: silver foam (denoted as "Foam"); etched silver foam (denoted as "Foam/E"); and etched silver foam coated with silver nanowires (denoted as "Foam/nanowires") (Figure 2b). Silver was selected as the cathode of choice because it mediates effective conversion of $\mathrm{CO}_{2}$ to $\mathrm{CO} \cdot{ }^{31,32}$ The Foam samples $(2 \mathrm{~cm}$ $\times 2 \mathrm{~cm} \times 200 \mu \mathrm{m}$ ) were prepared by washing commercially available silver foams with deionized (DI) water and isopropanol (IPA). The Foam/E electrodes were prepared by etching Foam in dilute nitric acid $\left(30 \% \mathrm{v} / \mathrm{v} \mathrm{HNO}_{3}\right)$ for 10 seconds (Figure $2 \mathrm{~b}$ ), where the Foam/nanowires electrodes were prepared by airbrushing an ink composed of $200 \mu \mathrm{L}$ silver nanowires solution (dispersed in $2 \mathrm{ml}$ of isopropyl alcohol) onto each side of the Foam/E electrode (Figure 2b).

Scanning electron microscopy (SEM) imaging of the porous Foam showed the silver foam skeletal structure consists of a smooth surface with few cracks and holes (Figure 2b). The etched surface of Foam/E contains a high number of cracks and holes (Figures 2b, S2). The silver nanowires with diameters of $\sim 70 \mathrm{~nm}$ were immobilized on the walls of the pores of the silver foam for the Foam/nanowires electrode (Figures $2 b, \mathrm{~S} 3, \mathrm{~S} 4$ ). The nanowires were observed from the surface to a depth of $60-100 \mu \mathrm{m}$ on each side of the foam (Figure S4). The X-ray diffraction (XRD) measurements of each electrode indicated signals at $38^{\circ}, 44^{\circ}$ and $64^{\circ}$ corresponding to metallic silver (111), (200) and (220) facets, respectively (Figure S5). These signals are consistent with metallic silver $\left(\mathrm{Ag}^{0}\right)$ being the main constituent of the samples. The electrochemical surface areas (ECSA) of the silver electrocatalyst in the Foam, Foam/E, Foam/nanowires and GDE/control, estimated from the double-layer capacitance $\left(\mathrm{C}_{\mathrm{dl}}\right)$ measurements (Figure $\mathrm{S} 6$ ), were significantly higher than that of the GDE/control. Etching the Foam to form Foam/E increased the ECSA by $\sim 1.2$-fold, while the addition of the nanowires to form Foam/nanowires exhibited a 2.6-fold increase in ECSA. Beyond changes in ECSAs, the intrinsic activity of the acid-etched Foam/E may also be higher than the Foam because of the rougher curved surfaces, which have been claimed to stabilize $\mathrm{CO}_{2}^{-}$intermediates (i.e., a higher 
roughness factor; roughness factor $=$ ECSA / geometric electrode area) ${ }^{33}$ Further modification with nanowires enhances the activity by increasing the abundance of exposed corner and edge active sites that promote chemisorption of both reactants and key intermediates. ${ }^{34,35}$ Additionally, The high length-to-diameter ratio afforded by nanowire decoration, provided excess pores and channels for the transport of $\mathrm{CO}_{2}$ and electrolyte that would result in a faster reaction rate. ${ }^{36}$

The three different silver foam electrodes were tested in a flow cell under constant applied current densities of 100, 200 and $300 \mathrm{~mA} \mathrm{~cm}{ }^{-2}$. Control experiments were performed with a CeTech ${ }^{\circledR}$ woven carbon cloth support containing a layer of silver nanoparticles (denoted as “GDE/control”). The GDE/control contains an MPL and PTFE common to gas-fed electrolyzers. ${ }^{37,38}$ Electrolysis experiments using GDE/control at an applied current density of $100 \mathrm{~mA} \mathrm{~cm}^{-2}$ for 500 seconds yielded a $\mathrm{FE}_{\mathrm{CO}}$ value of $33 \pm 6 \%$. This benchmark was exceeded by the Foam, which achieved a $\mathrm{FE}_{\mathrm{CO}}$ value of $52 \pm 2 \%$. This difference in $\mathrm{FE}_{\mathrm{CO}}$ was maintained over a 100-300 $\mathrm{mA} \mathrm{cm} \mathrm{cm}^{-2}$ range (Figure 4a). At $100 \mathrm{~mA} \mathrm{~cm}^{-2}$, the cell voltage $\left(\mathrm{V}_{\text {cell }}\right)$ of the Foam $(3.7 \pm 0.1 \mathrm{~V})$ was slightly higher than that of GDE/control $(3.4 \pm 0.1 \mathrm{~V}$, Figure S7). The higher cell voltages obtained with the foam electrodes relative to the GDE/control electrodes comes despite porous metals being two orders-of-magnitude more conductive than carbon GDLs (i.e., $\sim 10^{5} . \mathrm{S} \mathrm{m}^{-1}{ }^{39}$ c.f. $\left.\sim 10^{3} \mathrm{~S} \mathrm{~m}^{-1}\right)^{40}$. This difference in cell potentials may therefore be related to a relatively higher tortuosity compared to GDE/control electrodes, the foams retain larger volumes of the electrolyte which consequently introduces a greater solution resistance. Moreover, the contact resistances between the MPL and the membrane is lower. ${ }^{41}$ These factors are difficult to experimentally resolve in a dynamic flow cell environment. Nevertheless, there are several properties of silver foam electrodes that can be tuned to reduce voltage losses: thickness, pore size distribution, surface roughness, etc. 
The $\mathrm{FE}_{\mathrm{CO}}$ was further increased by the higher ECSA Foam/E to $59 \pm 6 \%$ at $100 \mathrm{~mA} \mathrm{~cm}{ }^{-2}$ while maintaining a similar $\mathrm{V}_{\text {cell }}(3.6 \pm 0.1 \mathrm{~V})$ to Foam. We operated a flow cell at $100 \mathrm{~mA} \mathrm{~cm}-2$ for $1 \mathrm{~h}$ and tracked the amount of $\mathrm{CO}$ and $\mathrm{CO}_{2}$ exiting the flow cell by GC. Experiments with Foam/E and GDE/control showed similar amounts of $\mathrm{CO}_{2}$ exiting the flow cell, but Foam/E generated a higher amount of $\left[i-\mathrm{CO}_{2}\right]$ relative to the $\mathbf{G D E} / \mathbf{c o n t r o l}$, and also produced a lower $\left[\mathrm{CO}_{2}\right]_{\text {outlet }}$ to $\left[i-\mathrm{CO}_{2}\right]$ ratio (Figure S8). The addition of the silver nanowires to the $\mathbf{F o a m} / \mathbf{E}$ increased $\mathrm{FE}_{\mathrm{CO}}$ to $72 \pm 3 \%$ at $100 \mathrm{~mA}$ $\mathrm{cm}^{-2}(3.7 \pm 0.1 \mathrm{~V}$; Figure $4 \mathrm{a})$. At $300 \mathrm{~mA} \mathrm{~cm}{ }^{-2}$, the Foam/nanowires yielded a $\mathrm{FE}_{\mathrm{CO}}$ of $34 \%$ at $300 \mathrm{~mA}$ $\mathrm{cm}^{-2}$, corresponding to a $\mathrm{H}_{2}: \mathrm{CO}$ ratio $(\sim 2)$ relevant to downstream chemical production. ${ }^{42}$ Note that we measured liquid product formation for all the preceding experiments using ${ }^{1} \mathrm{H}$ NMR spectroscopy, and determined that all $\mathrm{FE}_{\text {formate }}$ values were $<1 \%$ (Figure $\mathrm{S} 9$ ).

We observed that the efficiency of bicarbonate electrolysis could be improved by increasing the temperature of the electrolyte to $70{ }^{\circ} \mathrm{C}$ (Figure 4a). Using the $\mathbf{F o a m} / \mathbf{E}$ electrodes, an electrolyte temperature at the flow cell inlet of $70{ }^{\circ} \mathrm{C}$ yielded a $\mathrm{FE}_{\mathrm{CO}}$ of $78 \pm 4 \%$ at $100 \mathrm{~mA} \mathrm{~cm} \mathrm{~cm}^{-2}$ with a corresponding voltage of $3.5 \pm 0.1 \mathrm{~V}$ (c.f. $\mathrm{FE}_{\mathrm{CO}}$ of $59 \pm 6 \%$ at $20{ }^{\circ} \mathrm{C}$ ). Temperature can improve electrolyzer performance (i.e., improved $\mathrm{FE}_{\mathrm{CO}}$ ) in a number of ways. For example, higher temperatures lower $\mathrm{CO}_{2}$ solubility, thereby extracting more $\mathrm{CO}_{2}$ from the bicarbonate solution. ${ }^{43}$ Higher temperatures would also increase $\mathrm{CO}_{2}$ generation by increasing the bicarbonate dissociation kinetics (Eq. 7), ${ }^{44}$ and also shifts the equilibrium towards $\mathrm{CO}_{2}$ (Eq. $6, \Delta \mathrm{H}=11.77 \mathrm{~kJ} \mathrm{~mol}^{-1}$; Figure $\mathrm{S} 10$ ). These reactions also increase the $\mathrm{pH}$, thereby suppressing HER (Figure S11). This observation is supported by the GC measurements. Higher temperatures would yield faster mass transfer kinetics for $\mathrm{HCO}_{3}{ }^{-}$and $\mathrm{CO}_{2}$, which would also be expected to enhance the rate of bicarbonate electrolysis. ${ }^{45}$ 
(a)

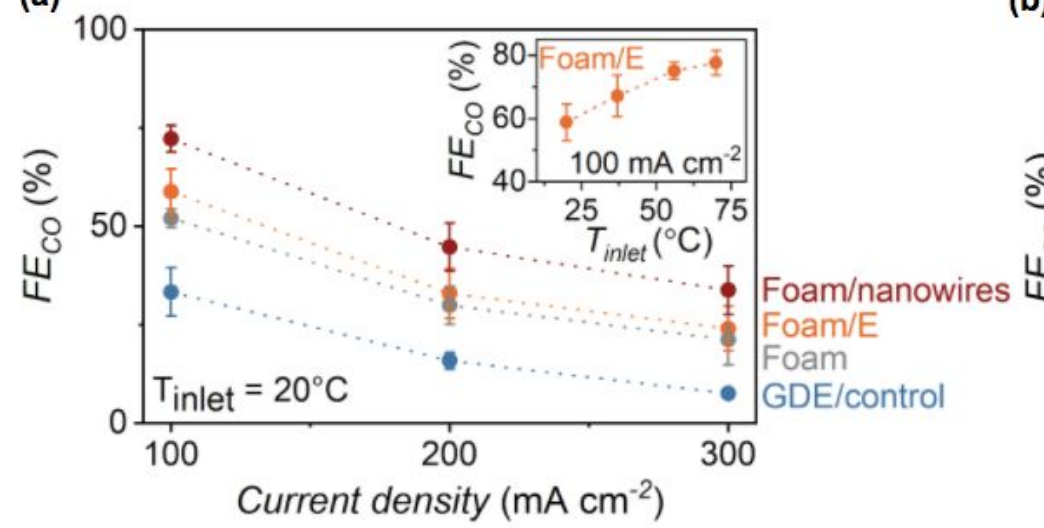

(b)

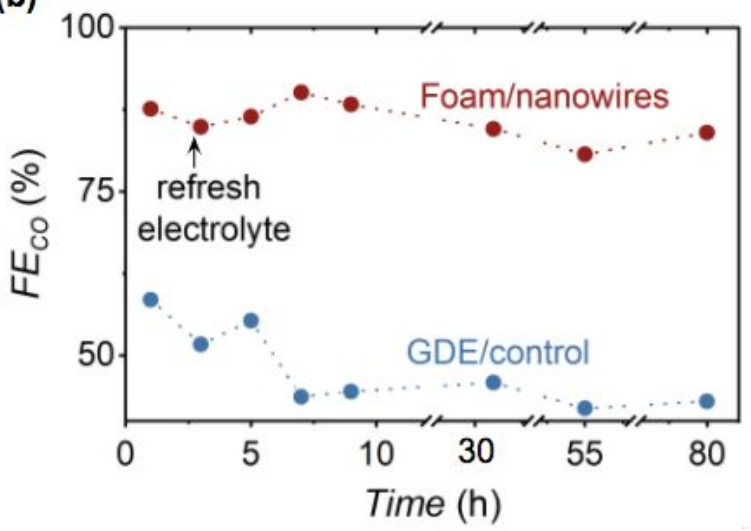

Figure 4. Catalytic performance of the free-standing foam electrodes and conventional GDEs. (a) $\mathrm{FE}_{\mathrm{CO}}$ as a function of current density for the four cathodic GDEs (geometrical surface area $=4$ $\left.\mathrm{cm}^{2} ; \mathrm{T}_{\text {inlet }}=20^{\circ} \mathrm{C}\right)$. Inset: $\mathrm{FE}_{\mathrm{CO}}$ values as a function of inlet temperature $\left(\mathrm{T}_{\text {inlet }}=20,37,56\right.$ and 70 ${ }^{\circ} \mathrm{C}$ ) at $100 \mathrm{~mA} \mathrm{~cm}{ }^{-2} . \mathrm{T}_{\text {inlet }}$ is the temperature of the bicarbonate solution entering the cathodic flowplate. The uncertainty is the standard deviation of 3 independent measurements. (b) $\mathrm{FE}_{\mathrm{CO}}$ at a constant applied current density of $65 \mathrm{~mA} \mathrm{~cm}{ }^{-2}\left(\mathrm{~T}_{\text {inlet }}=20{ }^{\circ} \mathrm{C}\right)$ for $80 \mathrm{~h}$ for the Foam/nanowires and the GDE/control electrodes.

Stability studies were performed by electrolysing $3.0 \mathrm{M}$ bicarbonate over 80 hours at an applied current density of $65 \mathrm{~mA} \mathrm{~cm}^{-2}$ using a flow cell containing Foam/nanowires or GDE/control (Figure 4b). (We used $65 \mathrm{~mA} \mathrm{~cm}^{-2}$ instead of $100 \mathrm{~mA} \mathrm{~cm}^{-2}$ to reduce the rate at which the bicarbonate reagent concentration decreased with time.) Bicarbonate concentrations were held constant by manually refreshing the $3.0 \mathrm{M} \mathrm{KHCO}_{3}$ electrolyte 500 seconds before each $\mathrm{GC}$ measurement. Unlike the catholyte solution, the $\mathrm{KOH}$ anolyte solution was not refreshed, since the continuous supply of $\mathrm{OH}^{-}$from the anion exchange side of the $\mathrm{BPM}$ is expected to maintain the $\mathrm{pH}$ of the anolyte. The $\mathrm{FE}_{\mathrm{CO}}$ decreased by merely 3\% over this $80 \mathrm{~h}$ period for Foam/nanowires. Notably, the GDE/control exhibited a much larger decrease of $16 \%$ over the same time period. SEM imaging of Foam/nanowires showed that the 
silver nanowires on the top of the silver foam surface remained intact (Figure S12), while the morphology of the silver nanoparticle catalyst layer in GDE/control electrode underwent much more dramatic morphological changes to yield a smoother surface after $80 \mathrm{~h}$ of electrolysis (Figure S13). The much higher operational stability of Foam/nanowires is consistent with the nominal changes in morphology and the nominal mass loss (Table S1). Moreover, the same Foam/nanowires electrode used for this $80 \mathrm{~h}$ electrolysis experiment could be reused 3 weeks later without any regeneration steps to yield nearly the same performance (Figure S14). These results demonstrate how a free-standing silver foam electrode does not suffer from silver nanoparticle detachment and stability issues common to conventional GDEs, such as GDE/control (Table S1).

\section{Conclusion}

A key outcome of this study is that we show that aqueous bicarbonate can be electrolyzed into a single carbon-based product more effectively than any known $\mathrm{CO}_{2}$ electrolyzer that uses an aqueous feedstock saturated with $\mathrm{CO}_{2}$, and nearly as effectively as electrolyzers that rely on gaseous $\mathrm{CO}_{2}$ feedstocks. We were able to achieve this by using a free-standing metallic cathodic GDE, which we found to be more effective for electrolyzing liquid bicarbonate solutions than the carbon-based GDEs widely used for $\mathrm{CO}_{2} \mathrm{RR}$ electrolysis. While a conventional GDE containing silver nanoparticles on a carbon support yields a $\mathrm{FE}_{\mathrm{CO}}$ of merely $33 \pm 6 \%$ during electrolysis of bicarbonate solutions, free-standing silver foam electrodes achieve a $\mathrm{FE}_{\mathrm{CO}}$ of $72 \pm 3 \%$. The electrolytic performance of this foam can be improved by increasing the ECSA (e.g., etching, coating with nanowires), or by operating at higher temperatures. Importantly, the free-standing electrodes are also far more stable than the conventional GDEs that suffer from catalyst detachment. The free-standing electrodes are also easier to 
assemble, and they can be re-used without further regeneration steps. We therefore contend that this architecture provides a viable path for making $\mathrm{CO}_{2}$ electrolysis compatible with carbon capture schemes.

\section{Experimental procedures}

\section{Cathode Preparation}

The silver foam and nickel foam were cut into desired dimensions $(2 \times 2 \mathrm{~cm})$ with a blade and washed with acetone and water. The silver foam $\left(0.085 \mathrm{~g} \mathrm{~cm}^{-2}\right)$ was treated with dilute nitric acid solution $\left(25 \% \mathrm{v} / \mathrm{v} \mathrm{HNO}_{3}\right)$ in a $50 \mathrm{ml}$ beaker for $10 \mathrm{~s}$ to remove the oxide layer and increase its

electrochemical surface area. The etched silver foam $\left(0.070 \mathrm{~g} \mathrm{~cm}^{-2}\right)$ was further washed thoroughly with deionized (DI) water, followed by a rinse with $3 \mathrm{M} \mathrm{KHCO}_{3} .200 \mu \mathrm{l}$ silver nanowires solution was dispersed in $2.0 \mathrm{ml}$ isopropyl alcohol (IPA) by sonication and was then hand-sprayed onto the etched silver foam substrate (silver nanowire loading: $5.90 \pm 0.46 \mathrm{mg}$ ). The prepared electrode was stored in DI water for further use.

To fabricate traditional GDEs with silver nanoparticles (GDE/control), a catalyst ink was prepared by mixing $315 \mathrm{mg}$ silver nanoparticles, $15 \mathrm{ml}$ DI water, $15 \mathrm{ml}$ IPA and $420 \mu \mathrm{l} \mathrm{Nafion}{ }^{\circledR} 117$ solution. The catalyst ink was then spray-coated on the carbon cloth to make multiple GDEs, and each GDE (geometric area: $4 \mathrm{~cm}^{2}$ ) has silver loadings of $3.7 \pm 0.1 \mathrm{mg} \mathrm{cm}^{-2}$.

\section{Controlled Temperature Experiments}

The catholyte reservoir was placed in a water bath with increased temperatures $\left(\mathrm{T}_{\text {bath }}\right)$ and was allowed to reach thermal equilibrium before electrolysis. The temperature of the catholyte entering the flow cell was measured right at the inlet of the cathode flow plate $\left(\mathrm{T}_{\text {inlet }}\right)$, since some heat losses were expected during the transfer of liquid from the reservoir to the flow cell. 


\section{Acknowledgements}

The authors would like to thank Dr. Tengfei Li and Arthur G. Fink for valuable discussions, David J. Dvorak for performing scanning electron microscopy (SEM) imaging, and Danika Wheeler for making resistance temperature detectors (RTD) for temperature measurements. The authors are grateful to Natural Resources Canada (EIP2-MAT-001), the Canadian Natural Science and Engineering Research Council (RGPIN 337345-13), Canadian Foundation for Innovation (229288), Canadian Institute for Advanced Research (BSE-BERL-162173), TOTAL American Services, Inc (an affiliate of TOTAL SA, France), and the Canada Research Chairs for financial support. This research was undertaken thanks in part to funding from the Canada First Research Excellence Fund, Quantum Materials and Future Technologies Program. SEM imaging was performed in the Centre for High-Throughput Phenogenomics at the University of British Columbia, a facility supported by the Canada Foundation for Innovation, British Columbia Knowledge Development Foundation, and the UBC Faculty of Dentistry.

\section{Author contributions}

C.P.B. supervised the project. Z.Z conceived the study and Z.Z, F.H., D.S., generated the figures. Z.Z. designed and executed the experiments. S.R. helped with electrolysis experiments. All authors contributed to the final manuscript writing.

\section{References}

1. Keith, D.W., Holmes, G., St. Angelo, D., and Heidel, K. (2018). A Process for Capturing CO2 from the Atmosphere. Joule 2, 1573-1594.

2. Weekes, D.M., Salvatore, D.A., Reyes, A., Huang, A., and Berlinguette, C.P. (2018). Electrolytic $\mathrm{CO}_{2}$ Reduction in a Flow Cell. Acc. Chem. Res. 51, 910-918. 
3. Salvatore, D.A., Weekes, D.M., He, J., Dettelbach, K.E., Li, Y.C., Mallouk, T.E., and Berlinguette, C.P. (2018). Electrolysis of Gaseous $\mathrm{CO}_{2}$ to $\mathrm{CO}$ in a Flow Cell with a Bipolar Membrane. ACS Energy Lett. 3, $149-154$.

4. Nitopi, S., Bertheussen, E., Scott, S.B., Liu, X., Engstfeld, A.K., Horch, S., Seger, B., Stephens, I.E.L., Chan, K., Hahn, C., et al. (2019). Progress and Perspectives of Electrochemical CO2 Reduction on Copper in Aqueous Electrolyte. Chem. Rev. 119, 7610-7672.

5. Burdyny, T., and Smith, W.A. (2019). CO2 reduction on gas-diffusion electrodes and why catalytic performance must be assessed at commercially-relevant conditions. Energy \& Environmental Science 12, $1442-1453$.

6. Welch, A.J., Dunn, E., DuChene, J.S., and Atwater, H.A. (2020). Bicarbonate or Carbonate Processes for Coupling Carbon Dioxide Capture and Electrochemical Conversion. ACS Energy Letters 5, 940-945.

7. Gao, D., Arán-Ais, R.M., Jeon, H.S., and Cuenya, B.R. (2019). Rational catalyst and electrolyte design for CO 2 electroreduction towards multicarbon products. Nature Catalysis 2, 198-210.

8. Smith, W.A., Burdyny, T., Vermaas, D.A., and Geerlings, H. (2019). Pathways to Industrial-Scale Fuel Out of Thin Air from CO2 Electrolysis. Joule 3, 1822-1834.

9. Butler, J.W., Jim Lim, C., and Grace, J.R. (2011). CO2 capture capacity of $\mathrm{CaO}$ in long series of pressure swing sorption cycles. Chemical Engineering Research and Design 89, 1794-1804.

10. Lin, S., Kiga, T., Wang, Y., and Nakayama, K. (2011). Energy analysis of CaCO3 calcination with CO2 capture. Energy Procedia 4, 356-361.

11. Li, T., Lees, E.W., Goldman, M., Salvatore, D.A., Weekes, D.M., and Berlinguette, C.P. (2019). Electrolytic Conversion of Bicarbonate into CO in a Flow Cell. Joule 3, 1487-1497.

12. Li, Y.C., Lee, G., Yuan, T., Wang, Y., Nam, D.-H., Wang, Z., García de Arquer, F.P., Lum, Y., Dinh, C.-T., Voznyy, O., et al. (2019). CO2 Electroreduction from Carbonate Electrolyte. ACS Energy Lett. 4, $1427-1431$.

13. Vermaas, D.A., and Smith, W.A. (2016). Synergistic Electrochemical CO2 Reduction and Water Oxidation with a Bipolar Membrane. ACS Energy Lett. 1, 1143-1148.

14. Li, J., Chen, G., Zhu, Y., Liang, Z., Pei, A., Wu, C.-L., Wang, H., Lee, H.R., Liu, K., Chu, S., et al. (2018). Efficient electrocatalytic CO2 reduction on a three-phase interface. Nature Catalysis 1, 592-600.

15. Weber, A.Z., and Newman, J. (2005). Effects of Microporous Layers in Polymer Electrolyte Fuel Cells. J. Electrochem. Soc. 152, A677-A688.

16. Kumar, S.S., and Himabindu, V. (2019). Hydrogen production by PEM water electrolysis--A review. Materials Science for Energy Technologies.

17. Dias, A.C. de B.V., and Others (2010). Chlor-alkali membrane cell process: study and characterization.

18. Xiang, C., Papadantonakis, K.M., and Lewis, N.S. (2016). Principles and implementations of electrolysis systems for water splitting. Materials Horizons 3, 169-173.

19. Zeng, K., and Zhang, D. (2010). Recent progress in alkaline water electrolysis for hydrogen production and applications. Progress in Energy and Combustion Science 36, 307-326. 
20. Franco, F., Prior, J., Velizarov, S., and Mendes, A. (2019). A Systematic Performance History Analysis of a Chlor-Alkali Membrane Electrolyser under Industrial Operating Conditions. NATO Adv. Sci. Inst. Ser. E Appl. Sci. 9, 284.

21. Achieved, S.E.S.C.B.E. (1985). Platinum Metals Activated Cathodes for the Chloralkali Industry. Platin. Met. Rev. 29, 98-106.

22. Lees, E.W., Goldman, M., Fink, A.G., Dvorak, D.J., Salvatore, D.A., Zhang, Z., Loo, N.W.X., and Berlinguette, C.P. (2020). Electrodes Designed for Converting Bicarbonate into CO. ACS Energy Letters, 2165-2173.

23. Larrazábal, G.O., Strøm-Hansen, P., Heli, J.P., Zeiter, K., Therkildsen, K.T., Chorkendorff, I., and Seger, B. (2019). Analysis of Mass Flows and Membrane Cross-over in CO2 Reduction at High Current Densities in an MEA-Type Electrolyzer. ACS Appl. Mater. Interfaces 11, 41281-41288.

24. Kutz, R.B., Chen, Q., Yang, H., Sajjad, S.D., Liu, Z., and Richard Masel, I. (2017). Sustainion Imidazolium-Functionalized Polymers for Carbon Dioxide Electrolysis. Energy Technology 5, 929-936.

25. Ren, S., Joulié, D., Salvatore, D., Torbensen, K., Wang, M., Robert, M., and Berlinguette, C.P. (2019). Molecular electrocatalysts can mediate fast, selective CO2 reduction in a flow cell. Science 365, 367-369.

26. Verma, S., Hamasaki, Y., Kim, C., Huang, W., Lu, S., Jhong, H.-R.M., Gewirth, A.A., Fujigaya, T., Nakashima, N., and Kenis, P.J.A. (2018). Insights into the Low Overpotential Electroreduction of CO2 to CO on a Supported Gold Catalyst in an Alkaline Flow Electrolyzer. ACS Energy Lett. 3, 193-198.

27. Diaz, L.A., Gao, N., Adhikari, B., Lister, T.E., Dufek, E.J., and Wilson, A.D. (2018). Electrochemical production of syngas from CO2 captured in switchable polarity solvents. Green Chemistry 20, 620-626.

28. Li, Y.C., Zhou, D., Yan, Z., Gonçalves, R.H., Salvatore, D.A., Berlinguette, C.P., and Mallouk, T.E. (2016). Electrolysis of CO2 to Syngas in Bipolar Membrane-Based Electrochemical Cells. ACS Energy Lett. 1, 1149-1153.

29. Delacourt, C., Ridgway, P.L., Kerr, J.B., and Newman, J. (2008). Design of an Electrochemical Cell Making Syngas ( $\mathrm{CO} \mathrm{H}[\mathrm{sub} 2])$ from $\mathrm{CO}[\mathrm{sub} 2]$ and $\mathrm{H}[\mathrm{sub} 2] \mathrm{O}$ Reduction at Room Temperature. Journal of The Electrochemical Society 155, B42.

30. Dufek, E.J., Lister, T.E., Stone, S.G., and McIlwain, M.E. (2012). Operation of a Pressurized System for Continuous Reduction of CO2. J. Electrochem. Soc. 159, F514.

31. Dutta, A., Morstein, C.E., Rahaman, M., Cedeño López, A., and Broekmann, P. (2018). Beyond Copper in CO2 Electrolysis: Effective Hydrocarbon Production on Silver-Nanofoam Catalysts. ACS Catal. 8, $8357-8368$.

32. Kottakkat, T., Klingan, K., Jiang, S., Jovanov, Z.P., Davies, V.H., El-Nagar, G.A.M., Dau, H., and Roth, C. (2019). Electrodeposited AgCu Foam Catalysts for Enhanced Reduction of CO2 to CO. ACS Appl. Mater. Interfaces 11, 14734-14744.

33. Lu, Q., Rosen, J., Zhou, Y., Hutchings, G.S., Kimmel, Y.C., Chen, J.G., and Jiao, F. (2014). A selective and efficient electrocatalyst for carbon dioxide reduction. Nat. Commun. 5, 3242.

34. Xi, W., Ma, R., Wang, H., Gao, Z., Zhang, W., and Zhao, Y. (2018). Ultrathin Ag Nanowires Electrode for Electrochemical Syngas Production from Carbon Dioxide. ACS Sustainable Chem. Eng. 6, 7687-7694.

35. Back, S., Yeom, M.S., and Jung, Y. (2015). Active sites of Au and Ag nanoparticle catalysts for CO2 
electroreduction to CO. ACS Catal. 5, 5089-5096.

36. Sun, D., Xu, X., Qin, Y., Jiang, S.P., and Shao, Z. (2020). Rational design of Ag-based catalysts for the electrochemical CO2 reduction to CO: a review. ChemSusChem 13, 39-58.

37. Weng, L.-C., Bell, A.T., and Weber, A.Z. (2018). Modeling gas-diffusion electrodes for CO2 reduction. Physical Chemistry Chemical Physics 20, 16973-16984.

38. Kim, B., Hillman, F., Ariyoshi, M., Fujikawa, S., and Kenis, P.J.A. (2016). Effects of composition of the micro porous layer and the substrate on performance in the electrochemical reduction of CO2 to CO. J. Power Sources 312, 192-198.

39. Feng, Y., Zheng, H., Zhu, Z., and Zu, F. (2003). The microstructure and electrical conductivity of aluminum alloy foams. Mater. Chem. Phys. 78, 196-201.

40. Ismail, M.S., Damjanovic, T., Ingham, D.B., Pourkashanian, M., and Westwood, A. (2010). Effect of polytetrafluoroethylene-treatment and microporous layer-coating on the electrical conductivity of gas diffusion layers used in proton exchange membrane fuel cells. J. Power Sources 195, 2700-2708.

41. Omrani, R., and Shabani, B. (2017). Gas diffusion layer modifications and treatments for improving the performance of proton exchange membrane fuel cells and electrolysers: A review. Int. J. Hydrogen Energy $42,28515-28536$.

42. Cao, Y., Gao, Z., Jin, J., Zhou, H., Cohron, M., Zhao, H., Liu, H., and Pan, W. (2008). Synthesis Gas Production with an Adjustable H2/CO Ratio through the Coal Gasification Process: Effects of Coal Ranks And Methane Addition. Energy Fuels 22, 1720-1730.

43. Lobaccaro, P., Singh, M.R., Clark, E.L., Kwon, Y., Bell, A.T., and Ager, J.W. (2016). Effects of temperature and gas-liquid mass transfer on the operation of small electrochemical cells for the quantitative evaluation of CO2 reduction electrocatalysts. Phys. Chem. Chem. Phys. 18, 26777-26785.

44. Johnson, K.S. (1982). Carbon dioxide hydration and dehydration kinetics in seawater 1. Limnol. Oceanogr. $27,849-855$.

45. Lobaccaro, P., Singh, M.R., Clark, E.L., Kwon, Y., Bell, A.T., and Ager, J.W. (2016). Effects of temperature and gas--liquid mass transfer on the operation of small electrochemical cells for the quantitative evaluation of CO 2 reduction electrocatalysts. Phys. Chem. Chem. Phys. 18, 26777-26785. 